\title{
DAVID SWARTZ
}

\section{Journey to Nowhere \\ The Grove 26 (2019)}

\author{
An old man \\ with a small voice \\ and a long trail of journeys \\ into the history \\ of hopes \\ dragging behind \\ shaved off his wrinkles \\ and walked into the future bakery \\ where he saw your sparkling eyes. \\ To himself: \\ I was search wild \\ for the present time \\ where the long spent past \\ finds the door-way \\ to the future \\ open'd wide; \\ and I found it \\ right here, right now \\ in a waking vision \\ of a lifesaving smile, \\ from out the portals \\ of your gracious soul \\ that filled my heart \\ with the momentary joy \\ of present bliss: \\ perpetual and eternal \\ is a moment like this!
}


Nowhere is a word which normally describes being lost. But nowhere can also be thought of as a kind of homeland or promised land, an authorial utopia of presence and immediacy, a non-place in which infinite conjunctive possibilities hang from the tree of the impossible. Nowhere gives hope to the lost postulates, has no determined body, no termination. Nowhere eschews then and there and affirms now and here, generates the future and the past yet remains forever present.

David Swartz is a young scholar, Masters Degrees in Comparative Literature (The University of Toronto) and Painting (The University of Lisbon). He is currently writing a $\mathrm{PhD}$ Thesis on Shakespeare's Sonnets at the Universidade NOVA de Lisboa. His recent translations include The Religious Mantle (New Meridian Arts, 2020), and And Painting: Questioning Contemporary Painting (CIEBA-FBAUL, 2016). His unpublished poems are of taut and inquisitive quality which bear witness to the existential uncertainty of human life in a credible metaphysical dimension as can be seen in his contribution to the 26 issue and the present one as well. 